\title{
Frontiers in Climate Change Adaptation science: advancing guidelines to design adaptation pathways
}

\section{Authors}

Dr./Hab. Alexandre K. Magnan (IDDRI, Sciences Po, 27 rue Saint-Guillaume, 75007 Paris, France \& LIENSs, La Rochelle University \& CNRS, La Rochelle, France)

Dr. E. Lisa F. Schipper (Environmental Change Institute, Oxford University Centre for the Environment, South Parks Road, Oxford, United Kingdom)

Pr. Virginie K.E. Duvat (LIENSs, La Rochelle University \& CNRS, La Rochelle, France

\section{Corresponding author}

Alexandre K. Magnan

Main postal address: IDDRI, Sciences Po, 27 rue Saint-Guillaume, 75007 Paris, France

alexandre.magnan@iddri.org; (+33) 0145497670

\section{Abstract}

Purpose of the review - This paper discusses three scientific frontiers that need to be advanced in order to support decision-makers and practitioners in charge of operational decisions and action on the design and implementation of concrete adaptation policies and actions. These frontiers refer to going beyond the (1) incremental vs. transformational and (2) maladaptation $v s$. adaptation dichotomies, and to advancing knowledge on (3) adaptation measures' effectiveness and roles in designing context-specific adaptation pathways.

Recent findings - Dealing with adaptation to climate change on the ground often means answering three obvious but critical questions: what to do, where and when? These questions challenge the scientific community's capacity to link conceptual advances (e.g. on transformative adaptation) and ground-rooted needs across sectors and regions (on solutions, governance arrangements, etc.).

Summary - We argue that the three above-mentioned frontiers represent the most burning challenges to the Adaptation Science community to help addressing climate-related societal needs. We also demonstrate that they are intertwined as moving one frontier forward will facilitate moving the others forward.

\section{Keywords}

Adaptation to climate change, incremental, transformational, maladaptation, measures' effectiveness

\section{Length of the manuscript}

- 5,194 words (Main text; excluding Figures, Figure captions and References).

- 2 figures, 0 Tables

- 60 References 


\title{
Frontiers in Climate Change Adaptation science: advancing guidelines to design adaptation pathways
}

\begin{abstract}
Purpose of the review - This paper discusses three scientific frontiers that need to be advanced in order to support operational decision-makers and practitioners in charge of operational decisions and action on the design and implementation of concrete adaptation policies and actions. These frontiers refer to going beyond the (1) incremental vs. transformational and (2) maladaptation $v s$. adaptation dichotomies, and to advancing knowledge on (3) adaptation measures' effectiveness and roles in designing context-specific adaptation pathways.

Recent findings - Dealing with adaptation to climate change on the ground often means answering three obvious but critical questions: what to do, where and when? These questions challenge the scientific community's capacity to link conceptual advances (e.g. on transformative adaptation) and ground-rooted needs across sectors and regions (on solutions, governance arrangements, etc.).

Summary - The three above-mentioned frontiers represent the most burning challenges to the Adaptation Science community in order to help addressing climate-related societal needs. We also demonstrate that they are intertwined as moving one frontier forward will facilitate moving the others forward.
\end{abstract}

\section{Keywords}

Adaptation to climate change, incremental, transformational, maladaptation, measures' effectiveness

\section{Introduction}

Together, the recently released special reports $[1,2,3]$ of the Intergovernmental Panel on Climate Change (IPCC) convey two clear messages. First, climate change-related risks to humankind and ecosystems will increase exponentially until societies implement workable solutions, both for avoiding the unmanageable by tackling the source of anthropogenic climate change (mitigation), and for managing the unavoidable part of climate impacts (adaptation). The Special Report on Ocean and Cryosphere in a Changing Climate shows, for example, that risk from sea-level rise (SLR) to low-lying coastal areas can be reduced by both mitigation and adaptation, even in the case of territories that are at the frontline of climate change impacts [4]. In urban atoll islands, for instance, risk by 2100 can be reduced 
from High ${ }^{1}$-to-Very $\mathrm{High}^{2}$ to Moderate ${ }^{3}$-to-High by moving from a still intense to a stringent global greenhouse gas emission scenarios. In addition, implementing adaptation at its maximum potential in urban atoll islands can help reduce risk from High-to-very High to High under an intense emission scenario, and from Moderate-to-High to close to Moderate in case of a stringent emission scenario.

Second, the IPCC special reports conclude that making the science-policy interface more effective, by addressing rising societal concerns and providing national to local decisionmakers with operational tools and answers, is critical for supporting short-to-long term risk reduction worldwide. With respect to climate change adaptation, key questions asked by decision-makers and practitioners in charge of operational decisions and action in terms of designing and implementing concrete adaptation policies and actions at the national and local levels, are relatively simple: what to do, where and when? That is, what type of adaptation responses are the most effective? Which locations are priority for implementation? And which timescales should be considered when planning for their implementation? From the perspective of the scientific community, these straightforward questions call for a more fundamental concern, i.e. to be in capacity to link conceptual advances (e.g. on transformative adaptation and maladaptation) and the real-world context-specific needs of decision-makers in charge of operational decisions (e.g., on solutions for adaptation, on how to best link short-term and long-term challenges when responding to climate risks, etc.).

This paper discusses three frontiers at the basic-fundamental research interface that are critical to bridging the adaptation science-policy gap, as well as advancing adaptation research toward climate-related societal needs more broadly. These frontiers are intertwined and refer to going beyond existing dichotomies and debates between (i) incremental vs. transformational and (ii) maladaptation $v s$. adaptation divides, and advancing knowledge on (iii) adaptation measures' effectiveness. For each of them, the text briefly describes why it is a scientific frontier and proposes some developments as food for thought, using coastal examples as real-world illustrations. It concludes on their intertwining and highlights the benefits to be expected from addressing these three frontiers together.

\section{Frontier 1 - The incremental vs. transformational divide}

\section{Point of departure}

Adaptation is defined as a process allowing organisms, ecosystems and human societies to adjust to the climate-related changes that have started to occur and, in the case of human societies, also to anticipate future risks $[5,6]$. Despite that it is a continuing adjustment, adaptation is often portrayed using dichotomies as such spontaneous $v s$. anticipated, or

\footnotetext{
${ }^{1}$ In the IPCC language, High means "significant and widespread" (e.g., [3]).

2 I.e. very high probability of severe impacts/risks and the presence of significant irreversibility or the persistence of climaterelated hazards (here, sea-level rise-related), possibly combined with the reaching of some adaptation limits.

${ }^{3}$ I.e. detectable and partly attributable to climate change (here, sea-level rise) with at least medium confidence.
} 
autonomous $v s$. planned, which originated in conceptual thinking in the early $1990 \mathrm{~s}[7,8]$. These dichotomies continue to be reflected in new framings that have emerged over the last decade and that distinguish between incremental and transformational adaptation [9]. Incremental adaptation refers to maintaining 'the essence and integrity of a system or process at a given scale' [10: 542], while transformational adaptation aims at changing 'the fundamental attributes of a social-ecological system in anticipation of climate change and its impacts' [10: 542]. Two well-known illustrations in flood-prone coastal areas are the implementation of hard engineering (assumed incremental) and managed retreat (assumed transformational; [11]). What we have experienced as scientists engaging with decisionmakers at large (both in charge of designing and implementing risk reduction and adaptation policies) and participating in scientific conferences, is that in the non-academic arena, as well as within the scientific arena, the incremental and transformational faces of adaptation are often opposed. The underlying rationale varies according to the stakeholder context, but the dichotomy remains there. Incremental adaptation is usually perceived by scientists [e.g. 12] as a short-term perspective that 'may not be sufficient to avoid intolerable risks' [13: 903], while transformational adaptation rather refers to what "should" be done to address the longterm challenges raised by climate change together with ensuring sustainability in natural and human systems. At another level, incremental adaptation is often seen by decision-makers as the most realistic and practical way forward, while transformation tends to be dismissed as politically infeasible, even if the need is acknowledged [e.g. 14]. This has perpetuated the distinction between these two forms of adaptation in academia, policy and practice, even when the incremental/transformative terms are not used. Surprisingly, creating such a dichotomy contradicts most of -if not all- the conclusions of scientific papers stating that making adaptation happen is complex and at the crossroads of multiple time, spatial and social scales.

\section{Scientific challenges ahead}

One of the biggest current debates centres around what sort of adaptation we should be aiming for, and what is sufficient to ensure well-being and survival. A misleading juxtaposition of incremental and transformational adaptation questions whether incremental adaptation can lead to transformation, and presumes that incremental and transformational are fundamentally contradictory. When taken in isolation, incremental measures may only have short-term benefits to risk reduction, which often has detrimental effects on a longer timescale because those measures tend to address exposure and vulnerability drivers only superficially, i.e. with a short view and at the expense of a longer-term vision. A typical example is engineered coastal protection structures as a response to shoreline erosion in nondensely populated areas. While offering direct protection, such structures often aggravate erosion [15], compromise the natural capacity of shorelines to naturally keep up with relative SLR [16], increase long-term vulnerability to larger events [17] and raise concerns in terms of affordability and maintenance requirements over time $[18,19]$. While hard protection could be part of the solution in very densely populated areas, it is generally unsustainable in more rural areas [4]. Similarly, in other contexts, development of small-scale irrigation for smallholder farmers can help overcome immediate issues with water insecurity, but may 
contribute to a lock-in effect and delay a transition away from agriculture that is likely to be necessary for many people living in dry environments, ultimately making people worse off [20]. This shows that depending on the context, incremental measures can become maladaptive if not part of a broader plan for enhancing adaptation, a point that the emerging and growing "adaptation pathway" approach captures [6]. Adaptation pathways highlight the need to sequence various types of measures over time in order to implement a long-term risk reduction strategy $[21,22,23,24]$. The most useful aspect of the pathways approach is the recognition that some measures can be initially beneficial, but could become obsolete or less effective over time, due to changing climatic and socio-economic conditions, while others that are not ready to be implemented now may become unavoidable in the future [25]. The need for sequencing actions also suggests to have a strategy for change that really addresses the root causes of exposure and vulnerability, which comes closer to the definition of "transformation" [10].

Understood therefore as a trajectory toward greater change, incremental strategies formulated as part of adaptation pathways suggest that small steps may add up to more significant transitions. Put differently, incremental measures can contribute to transformational adaptation if part of a broader adaptation pathway [12, 26, 27]. In reality, most transformational adaptation is unlikely to be operationalized without (partly) incremental responses. For example, coastal relocation of people, assets and activities, while increasingly recognized as of potential value for dealing with SLR impacts [4], is also acknowledged to face important limitations such as, among others, financial gaps, lack of institutional leadership and social reluctances [e.g. 28, 29, 30]. Implementing relocation therefore requires time - at least at a decadal pace- to convince people to be relocated, to overcome land tenure issues in destination areas, to preserve social networks and to identify financial compensation mechanisms, among others. In such a context of societal latency, and as coastal risks from SLR and increased wave height are already occurring and constantly increasing, maybe coastal protection (hard and soft) can, at least in some areas, serve as an interim strategy to reduce risks until a relocation strategy is developed. That is, planning for the long-term (transformational adaptation) may require intermediate strategies (incremental adaptation) to buy time, get societal consensus and lay foundations for more ambitious, in-depth action [12, $25,27,31]$. But this only works if the incremental strategies do not generate lock-in effects, i.e. come at the cost of reduced opportunities in the long term [32].

Communicating on such incremental-transformational intertwining is necessary in order to nudge decision-makers out of the inertia created by the short $v s$. long term dilemma, and promote both flexible and anticipatory strategies to manage risk. Adaptation science has a critical role to play here, especially through the analysis of the way the incrementaltransformational nexus operates in real-world examples, and in order to move away any incremental-transformational divide and instead emphasise complementarities [e.g. 12]. From a practical perspective, the adaptation pathways approach may offer a useful tool to drive such a knowledge shift [24, 26] (see Frontier 3). This perspective also acknowledges the turbulent and non-linear nature of transformation, which needs to be recognised in order to accommodate for the incremental and transitional steps involved [33]. 


\section{Frontier 2 - The Maladaptation-Adaptation continuum}

\section{Point of departure}

Another adaptation dichotomy includes judging "good" and "bad" adaptation and leads to an almost systematic opposition between adaptation and maladaptation [32]. In essence, maladaptation describes an action that results in undesirable and unintended outcome(s), and eventually increases exposure and vulnerability [10, 20, 34, 35]. However, most of the time, there is a very fine line between success and failure, depending for example on the group of population (adaptation for who?), spatial scale (e.g. is adaptation with side effects on other systems real adaptation?) and timescale (i.e. adapted until and by when?) considered. Thus, it is difficult to draw a clear line between what contributes to maladaptation, and what contributes to adaptation [36].

\section{Scientific challenges ahead}

There is consensus that adaptation-labelled measures can turn maladaptive, as illustrated by some post-catastrophe responses promoting in situ rebuilding [e.g. 34]. However, as shown with the "incremental vs. transformational" divide above (Frontier 1), measures that are maladaptive in the long run might still help the adaptation process on the short/medium term, depending on the duration of their implementation and if they are part of the broader, longer term risk reduction strategy. That means that maladaptation and adaptation form a continuum (example in Figure 1) along which the extent to which a given measure is considered detrimental or beneficial depends on both the extent of changes in environmental conditions (i.e. climate change-related) and societal choices (e.g. implementation process and timing, territorial scale considered, governance arrangements, capacity to anticipate future changes, societal acceptance of constraining measures, etc.) [36, 37]. While relevant options for the present can turn maladaptive due to changing climatic and socioeconomic conditions, such $a$ priori non-sustainable options could help trigger adaptation on the ground and therefore be part of a transformational path (see example of hard coastal protection above). The maladaptation-adaptation continuum needs to be fully acknowledged, highlighting the need for the scientific community to provide the decision-making arena with some concrete guidance on how to navigate from one side of the continuum to the other (see also Frontier $3)$.

\section{[INSERT FIGURE 1]}

To date, no agreed analytical framework for identifying maladaptation in real time has emerged, but some frameworks exist that provide useful starting points to understand maladaptation forms, spatial and time scales, etc. Three of these focus on an ex ante tracking of maladaptation in different sectors and contexts [32]. The oldest one, the Pathways framework, builds on the study of two engineering responses to water stress in Melbourne, 
Australia [39]. Based on the identification of the pathways through which maladaptation occurs, it highlights five guiding principles to limit maladaptation: (i) ensure that the initiative does not increase emissions of greenhouse gases; (ii) ensure economically and socially equitable initiatives; (iii) avoid high-cost initiatives; (iv) increase incentive to adapt; and (v) build flexibility into the initiative. The Precautionary framework [40] claims that 'since climate models and observation cannot provide what current decision-making frameworks need, the only solution is to amend these frameworks to make them able to take this uncertainty into account' [40: 242]. It suggests that identifying the option that is 'the most insensitive to future climate conditions' [40: 242] is more robust than looking for the best choice under one specific scenario, and advances six ways of intervention to avoid maladaptation: (i) no-regret strategies; (ii) reversible strategies; (iii) safety margin strategies; (iv) soft strategies; ( $v$ ) strategies that reduce decision-making time horizons; and (vi) the consideration of both conflicts and synergies between strategies. The Assessment framework relies on the assumption that adaptation requires that climate change, both sudden and slowonset events, is central to a broader approach to sustainable development [32]. It distinguishes between environmental, sociocultural, and economic maladaptation to highlight eleven guiding principles to minimize the risk of maladaptation: (i) avoid degradation that causes negative effects in situ; (ii) avoid displacing pressures onto other environments (neighbouring areas or areas that are connected ecologically or socioeconomically); (iii) support the protective role of ecosystems against current and future climate-related hazards; (iv) integrate uncertainties concerning climate change impacts and the reaction of ecosystems; (v) set the primary purpose as being to promote adaptation to climate-related changes rather than to reduce greenhouse gas emissions; (vi) start from local social characteristics and cultural values that could have an influence on risks and environmental dynamics; (vii) consider and develop local skills and knowledge related to climate-related hazards and the environment; (viii) call on new skills that the community is capable of acquiring; (ix) promote the reduction of socio-economic inequalities; $(x)$ support the relative diversification of economic and/or subsistence activities ; and (xi) integrate any potential changes in economic and subsistence activities resulting from climate change.

None of these frameworks suggests that there is a clear divide between actions contributing to maladaptation and actions contributing to adaptation. Rather, they indicate that whether a given intervention contributes to maladaptation or adaptation critically depends on, first, the balance through space and time between its benefits and its negative collateral effects (see Frontier 3), and second, the existence of a flexible and iterative decision-making process (including institutions, stakeholders and governance mechanisms) [e.g., 32, 37]. In other words, all of these frameworks suggest that enhancing adaptation to climate change is primarily about navigating across the maladaptation-adaptation continuum, and that no option is "bad" or "good" a priori.

\section{Frontier 3 - Assessing the effectiveness of adaptation measures}




\section{Point of departure}

The term "solutions" has become a buzzword in the climate policy and scientific arenas, especially in the run-up to the 21st Conference of the Parties of the United Framework Convention on Climate Change (COP21) in 2015, when the international community shifted from the design of the problem to the "era of solutions" [41]. However, Frontiers 1 and 2 above convey the message that there is a long way from measures to solutions. In particular, they suggest that locating a given measure along the maladaptation-adaptation continuum and deciding whether it serves a long-term transformational process or is only short-sighted, calls for understanding the potential benefits of such a measure in terms of risk reduction over time. Yet, there is still a huge gap today in scientifically-based approaches to assess potential effectiveness for a wide range of options, and according to different context-specificities. The knowledge gap prevents robust decisions on whether adaptation-labelled measures are potential solutions, until when, for whom and at which spatial scale; or are actually fallacious ideas.

\section{Scientific challenges ahead}

To especially support national to local decision-makers and practitioners in are charge of operational decisions on the design and implementation of concrete adaptation policies and actions, to navigate along the above-mentioned incremental-transformational pathway and maladaptation-adaptation continuum, assessment criteria are needed to describe the potential benefits of a given measure, the lifespan of such benefits, any undesirable side effects, and the barriers to implementation. Effectiveness is understood here as the degree to which a measure fulfils specified goals in terms of reducing climate change impacts and risks, and acknowledging that such goals highly depend on sociocultural context-specificities (values and choices) and can be debated. Building on a recent framing on ocean-based solutions for addressing climate change impacts [42], we propose the following eight criteria that we first describe, and then illustrate with a case study on the Maldives Islands. Together these eight criteria refer to three important dimensions for operational decision-making: the overall benefits to be expected from the measure in terms of climate risk reduction (hereafter the "core criteria"), the "societal enabling conditions" for implementing the measure, and the positive and negative "externalities" associated with the measure.

\section{$\underline{\text { Core criteria }}$}

- Potential effectiveness refers to the ability of the measure to reduce climate impacts to critical ecosystems, ecosystem services and societies (people, assets, infrastructures, etc.), and assuming its maximum implementation. Qualifying and measuring such effectiveness depends on the criteria used. Gattuso et al. [42], for example, assess the effectiveness of a given ocean-based measure against its ability to bridge the gap between impacts under low and high global greenhouse gas emission scenarios (i.e. RCP2.6 and RCP8.5). For some measures, such as ecosystem-based options, assessing effectiveness is however 
constrained by a lack of experience, implementation and long-term monitoring under changing climate-ocean conditions (SLR, sea surface temperature, $\mathrm{pH}$, etc.) $[15,16]$, which in turn hinders application [43]. For others, such as hard costal defences in densely populated areas, information exists based on quantitative engineering studies [4, 43].

- Readiness describes the actual stage of the measure's technical and technological development, suggesting some distinction between measures that are already partly deployed in situ, that are not deployed in situ but have been implemented elsewhere, and that are only at the proof-of-concept or theoretical stage (e.g. artificial floating islands to face SLR; [44, 45]). Readiness varies significantly across countries. For example, while The Netherlands are technologically ready to use mega-nourishment to reduce coastal risks ('sand engine' approach; [46]), Pacific atoll countries are at an early stage of testing beach nourishment through pilot projects [47].

- Lead time until full effectiveness describes the time needed to reach full implementation and effectiveness of the measure. For example, while planting mangrove may help reduce flood risk through reducing relative SLR, this measure requires time -time for the mangrove to be mature- to become fully effective. Other options refer to longer timescales, such as coastal retreat for example. Estimating this lead time is crucial to know from when this measure could become beneficial, therefore allowing to design the sequencing of actions involved in the related adaptation pathway [48, 49]. In the illustrative case below (next sub-section), three levels describe the lead time until full effectiveness: months (i.e. several months before benefits arise), years (i.e. a couple of years to a decade) and decades (i.e. more than a decade before effective outcomes).

- Duration of the benefits describes the duration of the positive effects to be expected once the measure is implemented. De facto, it also refers to the level of sustained commitment the measure requires to continue to produce benefits over time [42]. In the case of hard coastal defence, the duration of benefits is driven by both maintenance and upgrading of structures through strengthening and heightening [e.g., 19], while for restored ecosystems it is mainly controlled by the ability of the latter to adapt to climate pressures through various strategies (e.g. vertical growth and genetic evolution for corals; [50, 51]). As assessing the duration of benefits informs the potential obsolescence of the measure, it is complementary to the previous criteria to help locating the measure along the maladaptation-adaptation continuum and subsequently within the adaptation pathwayrelated sequence of actions. In the illustrative case below, four levels describe the Duration of the benefits: short-term (i.e. months to years), medium-term (i.e. from years to one to three decades), long-term (i.e. from three to five decades), and very long-term (i.e. five decades to a century).

\section{$\underline{\text { Societal enabling conditions }}$}

- Societal acceptability describes the capacity of the society or the community as a whole to support the implementation of a measure. For example, societal acceptability can be high for hard engineered coastal protection because in some contexts this latter creates a "sense of security" [17], as illustrated in the Maldives Islands where residents tend to prefer it to ecosystem-based measures [58]. In addition, there can be reluctances to the 
implementation of constraining measures (e.g. refusal of a coastal community to be relocated inland in Mauritius Island; [59, 60]) or of measures that will have only delayed and uncertain benefits, such as most of ecosystem-based options [43].

- Governability describes the potential for the measure to be implemented in a given decision-making governance context, especially by national and local public authorities as well as local community leaders. Such potential notably depends on the nature and degree of the socio-cultural, ecological and economic conflicts raised among stakeholders by the measure; on the capacity of the governance context to identify compromises [4]; and on the readiness of the national-to-local authorities to implement the measure. For example, on Reunion Island, Indian Ocean, the local authorities show a relatively low readiness to implement alternative measures to hard engineering as a result of a lock-in effect, i.e. business-as-usual vision of future change and response [14].

\section{Externalities}

- Potential co-benefits describe the additional benefits from the measure that are not related to those from the direct reduction of climate impacts. Co-benefits could include the improvement of other components of the socio-ecological system and, through this, the enhancement of other ecosystem services and better foundations for other measures. Ecosystem-based measures are well-known examples of options providing multiple cobenefits $[42,51]$. In addition to reducing flood risk, mangroves for example contribute to improved human well-being [53] through socio-cultural (e.g. protection of cultural sites), environmental (e.g. conservation of species that breed or live in mangroves) [55]; and subsistence and economic (e.g. provision of firewood, and support to commercial fisheries and tourism) [54] benefits. Social equity outcomes are also to be considered.

- Potential negative collateral effects describe the observed or anticipated adverse consequences of the measure either on the socio-ecological system in which it is implemented (e.g. inequity in accessing economic activities or food resources) or on other environments (i.e. neighbouring areas or areas that are connected ecologically or socioeconomically; e.g. hard coastal defence compromising sediment accumulation at the coast, in situ and/or downstream; $[16,32,56])$. This criterion refers to several guiding principles of the frameworks presented in Frontier 2 aimed at avoiding maladaptation, especially criteria (i) and (ii) of the Pathways framework; (ii) and (vi) of the Precautionary framework; and (i), (ii), (iv), (vi), (viii) and (xi) of the Assessment framework.

\section{From understanding effectiveness to designing and implementing adaptation pathways: a practical example}

Here we provide an illustration of how the above 8-criteria matrix could support decisionmaking towards robust climate adaptation pathways (Figure 2). We use the case of the Maldives Islands, Indian Ocean, in the face of SLR and build on recently published works highlighting, first, various island types according to the degree of human disruption of the capacity of the reef-island system to naturally adapt to SLR [57]; and second, adaptation pathways for each of these island types [25]. Supplementary Material SM1 briefly presents 
the island types. The example here considers two island types describing inhabited islands with relatively moderate population and assets densities (mean of $\sim 2,090 \mathrm{hab} . / \mathrm{km}^{2}$ in 2014), and very densely populated islands (mean of $\sim 6,860 \mathrm{hab} . / \mathrm{km}^{2}$, up to $\sim 65,700 \mathrm{hab} . / \mathrm{km}^{2}$ in the capital island of Male') (SM2). A set of five generic adaptation pillars (Figure 2, Panel B; see [25] for extended explanations) is considered under which a wide diversity of specific measures can be implemented. (i) Ecosystem resilience strengthening consists of options for maintaining or restoring, where possible, the marine and coastal ecosystems, in particular vegetated beach systems, mangroves, seagrass beds, and coral reefs. In the Maldivian context in particular, this adaptation pillar refers to maintaining both reef-to-island functional sediment transport pathways and accommodation space at the coast to allow continuous island adjustment (both vertical and horizontal) to ongoing environmental changes. (ii) Minimisation of the risk of maladaptation addresses the prevailing human-driven drivers that have operated over the last decades and contributed to past and current human exposure and vulnerability to SLR. An example of a practical measure experimented in the Maldives is the replacement of hard protection structures by soft devices, including the use of removable groynes (made of sand bags), to prevent human asset damage from seasonal sediment shift. (iii) Internal relocation considers the potential for relocating people, assets and activities within and between the Maldivian atolls, i.e. nationally. Such a pillar requires to consider island geomorphic characteristics (including size, elevation and exposure to storm surges), locally-available food resources (that is, nearshore reef fish and cultivable land), as well as island communities' social networks within the relocation area, and technical and financial support to relocation, which together drive societal acceptability. (iv) Island fortification associated with ground elevation refers to the protection of existing settlements by properly designed and built engineered structures (e.g. seawalls) and, in a context of SLR, some level of ground elevation. In the Maldives, this is ultimately illustrated by the $\sim 2 \mathrm{~m}$-high artificial island of Hulhumale' that has been developed since the 1990s to host the rapidly growing population of Male' and prevent SLR-driven damage. Therefore, hard coastal defences and island raising are examples of practical measures to be considered under this pillar. (v) International migration is considered a very last resort option in the case of a high-end climate-related ocean change scenario. Examples of practical measures deal with legal arrangements with hosting areas, and sociocultural action towards greater social acceptance of migration.

The assessment approach proposed in this paper identifies two main steps once the various adaptation-related measures have been identified by operational decision-makers and scientists. The first step consists in informing the "core criteria" (Potential effectiveness, Readiness, Lead time until full effectiveness, Duration of benefits) for the set of selected measures (e.g. use of removable groynes in (ii)) or at the adaptation pillar level (e.g. for internal relocation of a given island community), depending on the context. The aim here is to understand the potential of a specific measure or pillar to contribute, individually and/or together, to climate risk reduction. This is illustrated in Figure 2 by the move from Panel A to Panel B: when informed, the core criteria matrix serves as a starting point to design an adaptation pathway. An expert judgment-based approach could be used to conduct the assessment (Panel A in Figure 2), that is, for example, assess if a given measure has 
none/very low-to-low/moderate/high-to-very high Potential effectiveness to reduce SLR risk and Readiness; requires months/years/decades in terms of Lead time until full effectiveness; and would provide benefits (Duration of benefits) over a short-/medium-/long /very longterm scale. Panel B in Figure 2 provides an illustration of the outcome (i.e. design of adaptation pathways) at the adaption pillar level, for the two above-mentioned atoll island types. It especially uses a visual representation of the combination of the core criteria (righthand side of the legend of Panel B) that serves to position the adaptation pillars along a timescale (today, mid-century, end-century) and SLR scenarios (from low to high-end). The resulting context-specific adaptation pathways are detailed in [25]; the aim here is not to develop the underlying assessment, but to illustrate the usefulness of the assessment criteria to organize a set of measures/pillars over time by considering both their specific features and their potential connections with other measures/pillars.

The second step is represented by the move from Panel B to Panel C (Fig. 2), and consists of understanding the practical feasibility of the adaptation pathways. While the core criteria (Potential effectiveness, Readiness, Lead time until full effectiveness, Duration of the benefits) are foundational to the design of scientifically-sound adaptation pathways, they do not reflect the overall feasibility, in a given context, of the pathway as a whole. Such a feasibility actually crucially depends on the societal enabling conditions (Social acceptability, Governability) to decide if and how to operationalize the pathway, and on the analysis of the externalities (Co-benefits and Negative collateral effects) to put this adaptation strategy into the broader context of sustainable development. This step should especially involve the decision-makers and practitioners who are in charge of operational decisions relating directly or indirectly to climate risk reduction and adaptation. Involving the civil society and private stakeholders (e.g. professionals) is also recommended at this stage in order to be able to also consider connected dimensions such as, for example, social equity and economic competitiveness.

At the end, these two steps (from Panel A to Panel C) illustrate that when considered together, the eight criteria define the full assessment matrix that helps moving from "measures" to "solutions".

\section{[INSERT FIGURE 2]}

\section{Conclusion: intertwined frontiers}

The three scientific frontiers discussed in this paper are interconnected and, as a result, form a consistent storyline starting from reconciling the incremental-transformational dilemma in the aim of combining multiple solutions, benefiting from their synergies and avoiding trade-offs (Frontier 1), to better navigate along the Maladaptation-Adaptation continuum (Frontier 2) and assess the potential effectiveness of adaptation measures (Frontier 3, with both insights from and implications for Frontiers 1 and 2). From our vantage point, it seems necessary to locate a given measure along the maladaptation-adaptation continuum and decide to what 
extent it serves a long-term transformation process, if we are going to capture the potential benefits of such a measure in terms of risk reduction over time. Overall, we argue that advancing knowledge on these 3 Frontiers will be decisive to understand a given socioecological system's room for manoeuvre, and ultimately design robust long-term risk reduction strategies through the development of adaptation pathways. In this view, our paper specifically targets the national to local decision-makers and practitioners on the ground that are in charge of operational decisions and action in terms of designing and implementing concrete risk reduction and adaptation policies and actions.

Lastly, such intertwining means that moving one frontier forward will facilitate moving the others forward, which is expected to have a knock-on effect on scientific investigations. Two major benefits to be expected from moving forward these frontiers together relate, first, to providing the policy arena with both scientifically robust and pragmatic information, and second, given the urgency to act against climate change, to reducing delays in providing such information.

\section{Acknowledgements}

This work was supported by the French National Research Agency under the STORISK project (No. ANR15-CE03-0003). VKED was also funded by the INSeaPTION project, which is part of ERA4CS, an ERANET initiated by JPI Climate, and funded by FORMAS (SE), BMBF (DE), BMWFW (AT), IFD (DK), MINECO (ES), ANR (FR) with co-funding by the European Union (Grant 690462). AKM also thanks the ANR programme "Investissements d'avenir" (No. ANR-10-LABX-14-01).

\section{Ethic declarations}

\section{Conflict of Interest}

On behalf of all authors, the corresponding author states that there is no conflict of interest.

\section{Human and Animal Rights and Informed Consent}

This article does not contain any studies with human or animal subjects performed by any of the authors. 


\section{References}

1. IPCC. Summary for Policymakers. In: Masson-Delmotte V et al., editors. Global Warming of $1.5^{\circ} \mathrm{C}$. An IPCC Special Report on the impacts of global warming of $1.5^{\circ} \mathrm{C}$ above pre-industrial levels and related global greenhouse gas emission pathways, in the context of strengthening the global response to the threat of climate change, sustainable development, and efforts to eradicate poverty. Geneva: World Meteorological Organization, 2018.

2. IPCC. Summary for Policymakers. In: Masson-Delmotte V et al., editors. IPCC Special Report on Climate Change, Desertification, Land Degradation, Sustainable Land Management, Food Security, and Greenhouse gas fluxes in Terrestrial Ecosystems. In Press, 2019.

3. IPCC. Summary for Policymakers. In: Pörtner H-O, et al., editors. IPCC Special Report on the Ocean and Cryosphere in a Changing. In Press, 2019.

4. Oppenheimer M, Glavovic B, Hinkel J, van de Wal R, Magnan AK, Abd-Elgawad A, et al. Sea Level Rise and Implications for Low Lying Islands, Coasts and Communities. In: Pörtner H-O, et al., editors. IPCC Special Report on the Ocean and Cryosphere in a Changing. In Press, 2019.

5. Agard J, Schipper ELF, Birkman J, Campos M, Bubeux C, Nojiri Y, et al. Annex II: Glossary. In: Field CB, et al., editors. Climate Change 2014: Impacts, Adaptation, and Vulnerability. Contribution of Working Group II to the Fifth Assessment Report of the Intergovernmental Panel on Climate Change. Cambridge \& New York: Cambridge University Press; 2014.

6. Magnan AK, 2018. A theory of adaptation to climate change: from trajectories of vulnerability to adaptation pathways. Habilitation Thesis, University of la Rochelle. URL:

https://www.researchgate.net/publication/338385875 A theory of adaptation to climate change From trajectories of vulnerability to adaptation pathways? sg=ituOCnLgHUO qCKpNOYTHEamwywkmRLAVemAzAouamkOqu00AU-JLaVIRMgjJI-eXQHHqC2zE8MlxwL0QK-VWvRawB2L.

7. Smit B, Burton I, Klein RJT, Street R. The science of adaptation: a framework for assessment. Mitig Adapt Strateg Glob Chang 1999:4 :199-213. https://doi.org/10.1023/A:1009652531101.

8. Smith JB, et al. Vulnerability to climate change and reasons for concern: a synthesis. In: McCarthy J et al., editors. Climate Change 2001: Impacts, Adaptation, and Vulnerability. Cambridge: Cambridge Univ Press, 2001.

9. Pelling M. Adaptation to climate change: from resilience to transformation. London: Routledge, 2011.

10. Matthews JBR, et al. Annex I: Glossary. In: Masson-Delmotte V et al., editors. Global Warming of $1.5^{\circ} \mathrm{C}$. An IPCC Special Report on the impacts of global warming of $1.5^{\circ} \mathrm{C}$ above pre-industrial levels and related global greenhouse gas emission pathways, in the context of strengthening the global response to the threat of climate change, sustainable development, and efforts to eradicate poverty. Geneva: World Meteorological Organization, 2018.

11. Lawrence J, Boston J, Bell R, Olufson S, Kool R, Hardcaste M, Stroombergen A. Implementing pre-emptive managed retreat: constrains and novel insights. Current Clim Chang Rep 2020:6:66-80. https://doi.org/10.1007/s40641-02000161-z

12. Few R, Morchain D, Spear D, Mensah A, Bendapudi R. Transformation, adaptation and development: relating concepts to practice. Palgrave Commun 2017:3:17092. https://doi.org/10.1057/palcomms.2017.92.

13. Klein RJT, Midgley GF, Preston BL, Alam M, Berkhout FGH, Dow K, et al. Adaptation opportunities, constraints, and limits. In: Field CB, et al., editors. Climate Change 2014: Impacts, Adaptation, and Vulnerability. Contribution of Working Group II to the Fifth Assessment Report of the Intergovernmental Panel on Climate Change. Cambridge \& New York: Cambridge University Press; 2014.

14. Magnan AK, Duvat VKE. Unavoidable solutions or coastal adaptation in Reunion Island (Indian Ocean). Environ Sci Policy 2018:89:393-400. https://doi.org/10.1016/j.envsci.2018.09.002.

15. Morris RL, Konlechner TM, Ghisalbertii M, Swearer SE. From grey to green: efficacy of eco-engineering solutions for nature-based coastal defence. Glob Chang Bio 2017:5:1827-1842. https://doi.org/10.1111/gcb.14063.

16. Temmerman S, Meire P, Bouma T, Hermann PMJ, Ysebaert T, De Vriend HJ. Ecosystem-based coastal defence in the face of climate change. Nat Perspect 2013:504:79-83. https://doi.org/10.1038/nature12859.

17. Logan TM, Guikema SD, Bricker JD. Hard-adaptive measures can increase vulnerability to storm surges and tsunami hazards over time. Nat Sustain 2018:1:526-530. https://doi.org/10.1038/s41893-018-0137-6.

18. Burby RJ. Hurricane Katrina and the paradoxes of government disaster policy: bringing about wise governmental decisions for hazardous areas. Ann. Am. Acad. Polit. Soc. Sci. 2006:604:171-191. https://doi.org/10.1177/0002716205284676.

19. Hinkel J, Aerts JCJH, Brown S, Jiménez JA, Lincke D, Nicholls RJ, et al. The ability of societies to adapt to twentyfirst-century sea-level rise. Nat Clim Chang I 2018:8:570-578. https://doi.org/10.1038/s41558-018-0176-Z.

20. Antwi-Agyei P, Dougill AJ, Agyekum TP, Stringer LC. (2018) Alignment between nationally determined contributions and the sustainable development goals for West Africa. Clim Policy 2018:10:1296-1312. https://doi.org/10.1080/14693062.2018.1431199.

21. Wise R, Fazey I, Stafford Smith M, Park SE, Eakin HC, Archer Van Garderen ERM, et al. Reconceptualising adaptation to climate change as part of pathways of change and response. Glob Environ Chang 2014:28:325-336. https://doi.org/10.1016/j.gloenvcha.2013.12.002.

22. Werners SE, van Slobbe E, Bölscher T, Oost A, Pfenninger S, Trombi G, et al. Turning points in climate change adaptation. Ecol Soc 2015:20:3. http://dx.doi.org/10.5751/ES-07403-200403.

23. Zandvoort M, Campos IS, Vizinho A, Penha-Lopes G, Lorencova EK, ven der Brugge R, vend er Vlist M, ven den Brink A, Jeuken ABM. Adaptation pathways in planning for uncertain climate change: Applications in Portugal, the Czech Republic and the Netherlands. Environ Sci Policy 2017:78:18-26. Doi: 10.1016/j.envsci.2017.08.017. 
24. Haasnoot M, Brown S, Scussolini P, Jimenez JA, Vafeidis AT, Nicholls RJ. Generic adaptation pathways for coastal archetypes under certain sea-level rise. Env Res Commun 2019:1:071006. https://doi.org/10.1088/2515-7620/ab1871.

25. Magnan AK, Duvat VKE. Adaptation pathways for atoll islands. Insights from the Maldives. Reg Environ Chang 20:119. https://doi.org/10.1007/s10113-020-01691-w.

26. Solecki W, Pelling M, Garschagen M. Transitions between risk management regimes in cities. Ecol Soc 2017:22:38. https://doi.org/10.5751/ES-09102-220238.

27. Termeer CJAM, Dewulf A, Biesbroek GR, 2017. Transformational change: governance interventions for climate change adaptation from a continuous change perspective. J Environ Plan Manag 201760:558-576. https://doi.org/10.1080/09640568.2016.1168288.

28. Siders AR. Managed Retreat in the United States. One Earth 2019:1:216-225. https://doi.org/10.1016/j.oneear.2019.09.008.

29. Hauer ME, Fussell E, Mueller V, Burkett M, Call M, Abel K, et al. Sea-level rise and human migration. Nat Rev Earth Environ 2020:1:28-39. doi: 10.1038/s43017-019-0002-9.

30. Noy I. Paying a price of climate change: who pays for managed retreats? Current Clim Chang Rep 2020:6. https://doi.org/10.1007/s40641-020-00155-x

31. Park SE, Marshall NA, Jakku E, Dowd AM, Howden SM, Mendham E, Fleming A. Informing adaptation responses to climate change through theories of transformation. Glob Environ Chang 2012:22:115-126. https://doi.org/10.1016/j.gloenvcha.2011.10.003.

32. Magnan AK, Schipper ELF, Burkett M, Bharwani S, Burton I, Eriksen S, et al. Addressing the risk of maladaptation to climate change. Wires Clim Chang 2016:5:646-665. https://doi.org/10.1002/wcc.409.

33. Schipper ELF, Eriksen SE, Fernandez Carril LR, Glavovic BC, Shawoo Z. Turbulent transformation: abrupt societal disruption and climate resilient development, Clim and Dev 2020. https://doi.org/10.1080/17565529.2020.1799738

34. Juhola S, Glaas E, Linnér B-O, Neset T-S. Redefining maladaptation. Environ Sci Policy 2016, 55:135-140. https://doi.org/10.1016/i.envsci.2015.09.014.

35. Work C, Rong V, Song D, Scheidel A. Maladaptation and development as usual? Investigating climate change mitigation and adaptation projects in Cambodia. Clim Policy 2019:1:47-62. https://doi.org/10.1080/14693062.2018.1527677

36. Schipper E.L.F. Maladaptation: when adaptation to climate change goes very wrong. One Earth 2020:in press. https://doi.org/10.1016/i.oneear.2020.09.014.

37. Brown K, Naylor LA, Quinn T. Making Space for Proactive Adaptation of Rapidly Changing Coasts: A Windows of Opportunity Approach. Sustain 2017:9:1408. https://doi.org/10.3390/su9081408.

38. Singh C, Solomon D, Bendapudi R, Kuchimanchi B, Iyer S, Bazaz A. What shapes vulnerability and risk management in semi-arid India? Moving towards an agenda of sustainable adaptation. Env Dev $2019: 30: 35-50$. https://doi.org/10.1016/j.envdev.2019.04.007

39. Barnett J, O’Neill S. Maladaptation. Glob Environ Chang 2010:20:211-213. https://doi.org/10.1016/j.gloenvcha.2009.11.004.

40. Hallegatte S. Strategies to adapt to an uncertain climate change. Glob Environ Chang 2009:19:240-247. https://doi.org/10.1016/j.gloenvcha.2008.12.003.

41. UNFCCC. Lima-Paris Action Agenda. http://newsroom.unfccc.int/lpaa/, 2014.

42. Gattuso J-P, et al. Ocean solutions to address climate change and its effects on marine ecosystems. Front Mar Sci 2018:5:337. https://doi.org/10.3389/fmars.2018.00337

43. Nicholls RJ. Adapting to sea-level rise. In: Zommers Z, Alverson K, editors. Resilience: the science of adaptation to climate change. Amsterdam: Elsevier, 2018.

44. Owano N. Maldives floating island masterplan tests the waters. PhysOrg, 12 August 2012. https://phys.org/news/201208-maldives-island-masterplan.html.

45. Kitching C., 2015. Own a floating island: world's first ultra-luxury atolls to be built in the Maldives, Dubuai and Miami. MailOnline, 17 August 2015. https://www.dailymail.co.uk/travel/travel news/article-3197470/Forget-risingsea-levels-spoiling-paradise-islands-rich-build-World-s-ultra-luxury-floating-private-atolls-built-Maldives-DubaiMiami.html

46. Slobbe E, ed Vriend HJ, Aarninkhof S, Lulofs K, de Vries M, Dircke P. Building with nature: in search of resilient storm surge protection strategies. Nat Hazards 2013:66:1461-1480. https://doi.org/10.1007/s11069-013-0612-3.

47. Onaka S, Ichikawa S, Izumi M, Uda T, Hirano J, Sawada H. Effectiveness of gravel beach nourishment on Pacific Island. Asian Pacif Coasts 2017: 651-662. https://doi.org/10.1142/97898132338120059.

48. Haasnoot M, Middelkoop H, Offermans A, van Beek E, van Deurse WPA, 2012. Exploring pathways for sustainable water management in river deltas in a changing environment. Clim Chang 2012:115:795-819. https://doi.org/10.1007/s10584-012-0444-2.

49. Haasnoot M, Kwakkel JH, Walker WE, ter Maat J. Dynamic adaptive policy pathways: A method for crafting robust decisions for a deeply uncertain world. Glob Environ Chang 2013:23:485-498. https://doi.org/10.1016/j.gloenvcha.2012.12.006.

50. Hughes TP, Barnes ML, Bellwood DR, Cinner JE, Cumming GS, Jackson JBC, et al. Coral reefs in the Anthropocene. Nat 2017:546: 82-90. https://doi.org/10.1038/nature22901.

51. Perry CT, Alvarez-Philip L, Graham NAJ, Mumby PJ, Wilson SK, Kench PS, et al.. Loss of coral reef growth capacity to track future increases in sea level. Nat 2018:558:396-400. https://doi.org/10.1038/s41586-018-0194-z.

52. Pontee N, Narayan S, Beck MW, Hosking AH. Nature based solutions: lessons from around the world. MaritEngin J 2016:169:29-36. https://doi.org/10.1680/jmaen.15.00027. 
53. Scarano FR. Ecosystem-based adaptation to climate change: concept, scalability and a role for conservation science. Perspect Ecol Conserv 2017:15:65-73. https://doi.org/10.1016/j.pecon.2017.05.003.

54. Tanner MK, Moity N, Costa MT, Marin Jarrin JR, Aburto-Oropeza O, Salinas-de-Léon P. Mangroves in the Galapagos: ecosystem services and their valuation. Ecol Econ 2019:160:12-24. https://doi.org/10.1016/j.ecolecon.2019.01.024.

55. Hills T, Carruthers TJB, Chape S, Donohoe P. A social and ecological imperative for ecosystem-based adaptation to climate change in the Pacific Islands. Sustain Sci 2013:8:455-467. https://doi.org/10.1007/s11625-013-0217-5.

56. Kates RW, Colten CE, Laska S, Leatherman SP. Reconstruction of New Orleans after Hurricane Katrina: A research perspective. Proc Natl Acad Sci 2006:40:14653-14660. https://doi.org/10.1073/pnas.0605726103.

57. Shaig A. Survey of CC adaptation measures in Maldives. Integration of Climate Change Risks into Resilient Island Planning in the Environment. Male, 2011.

58. Anisimov A, Magnan AK, Duvat VKE. Strengths and gaps of coastal risk governance in Mauritius Island, Indian Ocean. Environ Sci Policy 2020:20:110. https://doi.org/10.1007/s10113-020-01699-2

59. Dow K, Berkhout F, Preston BL, Klien RJT, Midgley G, Shaw R. Limits to adaptation. Nat Clim Chang 2013:3:305307. https://doi.org/10.1038/nclimate1847.

60. Duvat VKE, Anisimov A, Magnan AK. Assessment of coastal risk reduction and adaptation-labelled responses in Mauritius Island (Indian Ocean). Reg Env Chang 2020:20:110. https://doi.org/10.1007/s10113-020-01699-2. 


\section{Figures}

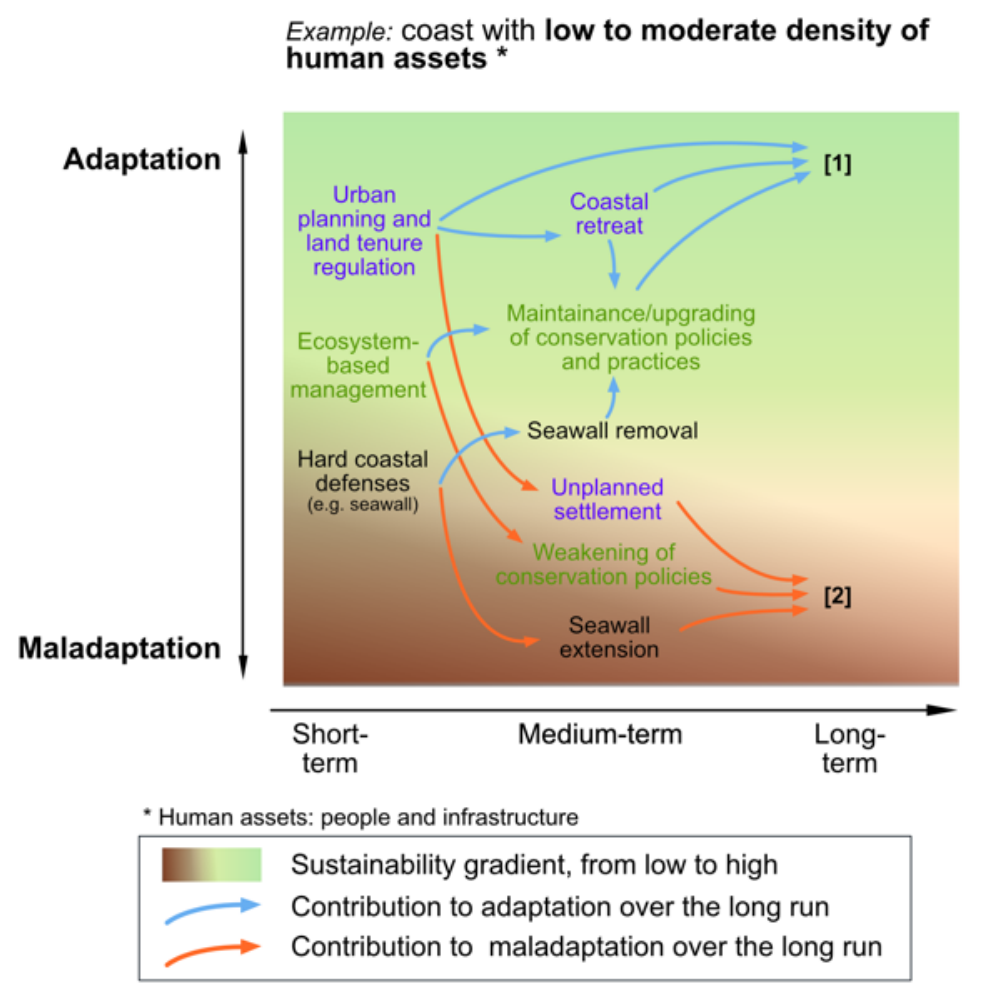

Fig. 1. Stylized representation of the maladaptation-adaptation continuum. The maladaptation-adaptation continuum is represented on the $\mathrm{Y}$ axis of both panels. The background colour graduation from brown to light green illustrates a transition from unsustainable practices to long-term adaptation supporting sustainable development in a changing climate. The arrows represent the life span of a given measure, and its connection to a subsequent one; blue and orange arrows illustrate adaptive and maladaptive pathways, respectively. The panel provides an illustration of a coastal areas (e.g. a rural atoll island) with low to moderate density of human assets (here, people and infrastructure) at risk from sea-level rise, and starting with three generic types of responses (urban planning and land tenure regulation, ecosystem-based management and hard coastal defences). The weakening of planning processes and conservation policies in the coming decades, together with the strengthening of the hard defence strategy, describe a maladaptive path as such a combination of options generate lock-in effects in terms of increased exposure of settlements, continuous degradation of ecosystems and dependence to external funding. On the opposite, the shift from a hard-engineered strategy to enhanced ecosystem conservation and planned and local relocation could lay the foundations for an adaptive pathway. 


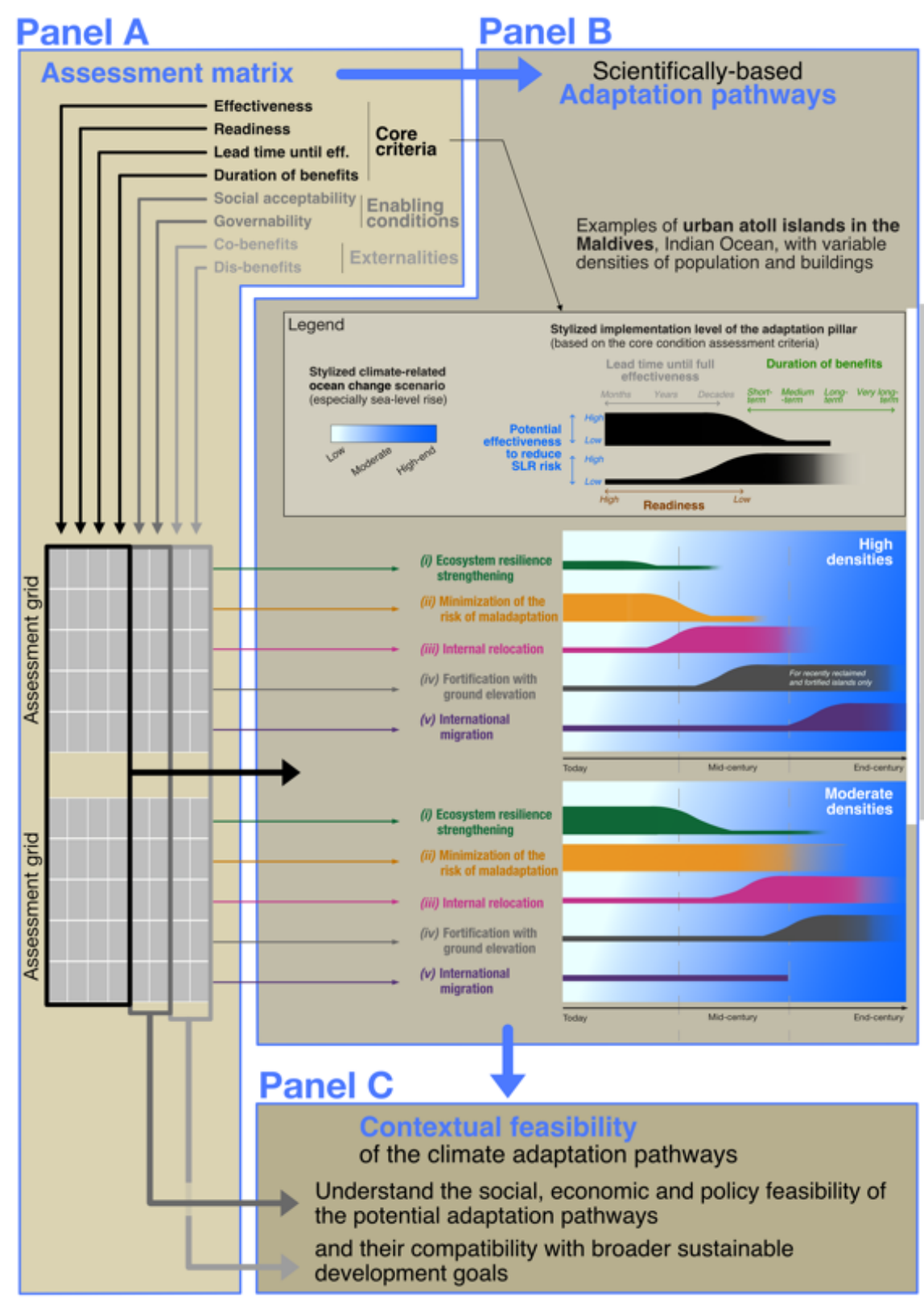

Fig. 2. From the assessment matrix to the design of adaptation pathways. Panel A illustrates the 8criteria assessment matrix described in the main text. Using a concrete case in the Maldives, Panel B translates these results into a pathway visualisation combining the core criteria of the assessment matrix (Potential effectiveness to reduce SLR risk, Readiness, Lead time until full effectiveness, Duration of the benefits), based on the framing presented in right-hand side of the legend. Panel $\mathbf{C}$ highlights the need to consider the other four criteria (Social acceptability, Governability, Co-benefits and Dis-benefits) to address the critical questions of the feasibility of the scientifically-based adaptation pathway as well as this latter's compatibility with broader policy challenges. 